International Journal of Applied Linguistics \& English Literature

ISSN 2200-3592 (Print), ISSN 2200-3452 (Online)

Vol. 1 No. 7; November 2012 [Special Issue on Applied Linguistics]

\title{
Learners' Identity Construction in the Context of English as an International Language
}

\author{
Luis Guerra \\ University of Evora \\ Largo dos Colegiais, 2, 7004-516, Evora, Portugal \\ Tel: 351-266740800Ｅ-mail:1spg@uevora.pt
}

Received: 28-09- 2012

Accepted: 26-10- 2012

Published: 25-11- 2012

doi:10.7575/ijalel.v.1n.7p.117

URL: http://dx.doi.org/10.7575/ijalel.v.1n.7p.117

\begin{abstract}
According to Riley (2007) the term 'identity' can be used to talk about what makes individuals just that, individual, who self-reports using the pronoun 'I', which is subjective and private. On the other hand, we can also use 'identity' to talk about what makes this individual like other individuals in terms of shared characteristics and memberships, the 'you' that others address and construct, report on and to. These two spheres, the collective and individual identities, exist and impact on one another reciprocally. In these circumstances, the construction of self is a continuous process. This paper aims to explore connections between identity construction and language use within the context of English as an international language. More specifically, it focuses on the Portuguese learners' own perceptions of their language use and on their discursive construction of identities, identifying the negotiations implied in the process of collective and individual identities construction.
\end{abstract}

Keywords: Identity construction, individual identity, collective identity, linguistic markers, language ownership, English as an International Language

\section{Introduction}

Identity formation, the development of an individual's distinct personality, has been a central topic explored by theorists and researchers around the world. For example, West (1992) (in Norton, 1997) believes that identity relates to the desire for recognition, for affiliation, and for security and safety. Norton (1997) proposes that identity is "how people understand their relationship to the world, how that relationship is constructed across time and space, and how people understand their possibilities for the future" (p.410). Emphasizing the linguistic component of identity formation, Norton adds that every time language learners speak, "they are constantly organizing and reorganizing a sense of who they are and how they relate to the social world. They are, in other words, engaging in identity construction and negotiation" (p.410).

However, the process of identity formation not only defines individuals to themselves but also to others. Besides a sense of uniqueness from others, it should include a sense of continuity and of affiliation. Cerulo (1997) affirms that collective identity "addresses the 'we-ness' of a group, stressing the similarities or shared attributes around which group members coalesce" (p.386). Moreover, Schöpflin (2001) suggests that "collective identity provides a sense of security for its members by making the world meaningful, permitting intra-collectivity communication and constructing collective forms of knowledge that allow the individual to lead a life without having constantly to make (new) sense of whatever phenomena he/she encounters" (p.3). Schöpflin stresses the fact that collective identities establish boundary mechanisms and boundary filters to "ensure that ideas external to the community are never received in full, for if they were, they could devastate the sense of collective self by introducing a tidal wave of innovation which the receiving community had no cognitive means of ordering" (pp.3-4). Schöpflin reckons the importance of boundaries because if you "break them down, far from promoting 'emancipation', (it) generates insecurity and, most likely, the polar opposite of emancipation, resistance, drawing in and higher boundary fences" (p.4). Finally, Schöpflin suggests that "anything can be a boundary marker, from diet to dress codes, but probably the single most important of these divides is language" (pp.5-6). Taking that in consideration, this study aims at examining the connections between identity construction and language use considering Portuguese English learners' own perceptions of their language use and their discursive construction of identities. 
International Journal of Applied Linguistics \& English Literature

ISSN 2200-3592 (Print), ISSN 2200-3452 (Online)

Vol. 1 No. 7; November 2012 [Special Issue on Applied Linguistics]

\section{The study}

The research question of the study (Does the English language affect the identities of young adults in Portugal?) intended to identify the students' perception of their individual and collective identities as far as their use of English is concerned. It is important to note that there has been little research on the influence of linguistic markers, as far as English as a foreign and international language is concerned, in the learners' construction of identity. Furthermore, in order to complement this study and fully answer the research question, the results of three previously carried out studies concerning different aspects of learners' identity construction and language use will be analyzed: (1) students' attitudes toward English as an international language (Guerra, 2009), (2) students' attitudes toward the emergence of a Portuguese variety of English (Portuguese English) (Pernão, 2010) and (3) students' attitudes toward the use of English borrowings and how language is used to construct youth identity (Gomes, 2008). In essence, based on the findings of the main study and the complementary studies, four aspects of identity construction will be analyzed: (1) individual and collective identity construction, (2) the concept of language ownership, (3) the emergence of Portuguese English, and (4) the use of English borrowings. It is hoped that when these factors are put together, they provide a comprehensive and objective description of how language markers in general, and the English language in particular, contribute to the identity construction of young adults in Portugal.

\section{Main study: Individual and collective identity construction}

The identification of the students' individual and collective identities in this study follows Groebner's (2004, in Edwards, 2009) remarks that "identity can refer to an individual's own subjective sense of self, to personal classification 'markers' that appear as important, both to oneself and to others, and also to those markers that delineate group membership(s)"(p.16). Consequently, this study made use of two surveys, one to identify the students' construction of individual identity (personal classification markers) and another concerning their collective identity (group membership markers).

\subsection{Individual identity: Constructing my identity - Who am I?}

Students (Sample size/ $\mathrm{N}=39$ ) in three $1^{\text {st }}$ cycle/B.A. courses at the University of Evora, Portugal (Languages, Literatures and Cultures - LLC; $N=14$, Information and Documentation Sciences - IDS; $N=18$, Nursing NUR, $\mathrm{N}=7$ ) were asked to complete a questionnaire in a table format with 21 blank spaces with one-word answers to the question 'Who am I?'. Data analysis showed that the students' answers could fall into seven distinct categories: Gender, Occupation, Family Relationships, Activities, Relationship with Others, Nouns, and Adjectives.

Based on the students' answers, the following list identifies the category, the number of different answers in the category in parentheses, each answer within that category, and the amount of times that answer was mentioned in parentheses, when more than once:

- Gender (1): woman (4).

- Occupation (4): student (4), journalist, teacher, decorator.

- Family Relationships (11): daughter (5), sister (4), cousin (3), granddaughter, mother (2), niece, godmother, goddaughter, son, brother, nephew.

- Activities (18): sports, (listening to) music, reading (3), cooking (2)/baking cakes, singing, eating, (TV) spectator, (using) computers, (using) facebook, driver, rock fan, writer, drawing, taking pictures, travelling/abroad, meditating, painting.

- Relationship with Others (12): kind/nice to others (24), friend(ly) (23), companion, girlfriend (2), boyfriend, girl scout, citizen, lover, classmate, single, bad (to others who are mean to her), helper, listener, carer.

- Adjectives (102): stubborn (20), happy (11), dreamer, fun (9), absent minded, perfectionist (7), responsible, (hard) worker (6), ambitious, persistent, sensitive, lazy, humble, talkative, proud, good mood (5), glutton, fighter, determined, organized, insecure, observer (4), thinker, adventurous, spoiled, listener, worried (3), short, complicated, smart, patient, nostalgic, peaceful, (...) (2), thin, romantic, fair, honest, generous, leader, (...).

- Nouns (30): Benfica (3), sporting (2), laughter, knowledge, love (2), ( $\rightarrow$ Adj) dissatisfaction, contradiction, contemplation, introspection, sincerity, communication; hair, jokes, allergies, extremes, freedom, (hate) skirt, blond guys, experiences, analysis, parties, God, Erasmus, Portugal, order, utopia, disorder; languages, (likes) English, (better at) English (than) Portuguese.

Table 1 shows the categories from students' answers and the number/percentage of all answers that appeared in each category. 
International Journal of Applied Linguistics \& English Literature

ISSN 2200-3592 (Print), ISSN 2200-3452 (Online)

Vol. 1 No. 7; November 2012 [Special Issue on Applied Linguistics]

\begin{tabular}{lc} 
Table 1. Categories and number/percentages of occurrence \\
\hline & $\begin{array}{c}\text { Total number of } \\
\text { occurrences }(\mathrm{N} / \%)\end{array}$ \\
\hline Adjectives & $254(62.3 \%)$ \\
Relationship with Others & $59(14.5 \%)$ \\
Nouns & $36(8.8 \%)$ \\
Activities & $26(6.4 \%)$ \\
Family Relations & $22(5.4 \%)$ \\
Occupation & $7(1.7 \%)$ \\
Gender & $4(1.0 \%)$ \\
TOTAL & $408(100 \%)$ \\
\hline
\end{tabular}

$(\mathrm{N}=$ sample size $)$

According to Edwards (2009), "language can certainly be considered as a 'marker' at the individual level" (p.21). However, the identification of the students' first (Portuguese) and second languages (English) appeared only twice, as one student remarked that she liked English and another that she is better at English than Portuguese, as markers of their individual identity.

\subsection{Collective identity: I and the Others}

Most students who answered the survey on individual identity construction also participated in the survey $(\mathrm{N}=$ 41 ; $\mathrm{LLC}=14$, IDS $=14$, NUR $=13$ ) that aimed at perceiving their collective identity formation as far as language markers are concerned.

After Riley's (2007) parameters of social identity and the categories identified in the previous study (individual identity), students filled in a table with the heading 'I and the Others' displaying 13 categories: Religion, Politics, Nationality, Hobbies/Sports, Age, Occupation, Marital Status, Gender, Family Relations, Place of Birth, Race/Ethnicity, Place of Residence, and Language(s). In order to complete the table, students were asked to provide personal information in each category. Although students provided answers to all categories of collective identity, due to the aim of this study, only their responses to the category 'Language(s)' will be analyzed.

However, it seems important to identify their nationality because it is certainly related to the languages they would eventually point out. Table 2 shows the nationalities of respondents.

Table 2. Students' nationalities.

\begin{tabular}{lc}
\hline & $\mathrm{N}(\%)$ \\
\hline Portuguese & $36(88 \%)$ \\
Dual Citizenship & $4(10 \%)($ Port/Luxembourger, Port/Swiss, \\
& Port/French, Port/Moldovan) \\
Foreign & $1(2 \%)(\mathrm{Czech})$ \\
TOTAL & $41(100 \%)$ \\
\hline
\end{tabular}

After examining data concerning students' languages, Portuguese, English and a few other foreign languages were recorded.

\subsubsection{Identification of the Portuguese language}

All subjects identified the Portuguese language as a marker of their collective identity. The Czech subject (LLC, ERASMUS) provided the following languages, "Czech/German/English/Portuguese", and the Portuguese/French subject (LLC) put down "French/Portuguese/English". These answers might indicate that the order of the identification of languages might be a relevant piece of information in the students' identity construction. However, two other subjects presented some thought-provoking data as the Portuguese/Luxembourger subject (LLC) listed "Portuguese/French/German/Luxembourgish/English" as her languages, and a Portuguese subject (LLC) identified "English/Spanish/Portuguese/French". Predictably, all other subjects put the Portuguese language first.

\subsubsection{Identification of the English language}

Surprisingly, only 21 subjects (51\%) identified the English language. Interestingly, English was not referred to by 1 LLC subject ( $7 \%$ of all LLC students), 7 NUR subjects ( $54 \%$ of all NUR students) and 12 IDS subjects 
International Journal of Applied Linguistics \& English Literature

ISSN 2200-3592 (Print), ISSN 2200-3452 (Online)

Vol. 1 No. 7; November 2012 [Special Issue on Applied Linguistics]

(79\% of all IDS students). In addition, the Portuguese/Luxembourger subject added the symbol "(+/-)" to the English language and one Portuguese subject (NUR) added "(reading skills)" to the identification of the French language. On reflection, students seemed to regard their competence level in the language as a significant factor in the recognition of that language as a marker of their identity.

\subsubsection{Identification of other foreign languages}

Besides English, other foreign languages such as French, Italian, German, Spanish, Czech, Luxembourgish, and Moldovan were pointed out by students. It seems relevant to stress that among the students who referred to a foreign language, six did not identify English (1 LLC, 4 IDS and 1 NUR). Tables 3, 4 and 5 show the languages identified by the respondents.

Table 3. Languages referred to by students ( $L L C, N=14$ )

\begin{tabular}{lc}
\hline & Language(s) \\
\hline Portuguese & Portuguese/English/Italian \\
Czech & Czech/German/English/Portuguese \\
Portuguese & Portuguese/English $(\mathrm{N}=4)$ \\
Portuguese & Portuguese/Spanish \\
Portuguese/French & French/Portuguese/English \\
Portuguese & Portuguese/English/Spanish \\
Portuguese & Portuguese/Spanish/English/French \\
Portuguese/Luxembourger & Portuguese/French/German/Luxembourgish/English \\
Portuguese & Portuguese/Spanish/English/(French) \\
Portuguese & Portuguese/German/English \\
Portuguese & English/Spanish/Portuguese/French \\
\hline
\end{tabular}

Table 4. Languages referred to by students (IDS, $\mathrm{N}=14$ )

\begin{tabular}{lc}
\hline & Language(s) \\
\hline Portuguese & Portuguese $(\mathrm{N}=8)$ \\
Swiss/Portuguese & Portuguese/German \\
Portuguese & Portuguese/Italian \\
Portuguese & Portuguese/Spanish $(\mathrm{N}=2)$ \\
Portuguese & Portuguese/English $(\mathrm{N}=2)$ \\
\hline
\end{tabular}

Table 5. Languages referred to by students (NUR, $\mathrm{N}=13$ )

\begin{tabular}{lc}
\hline & Language(s) \\
\hline Portuguese & Portuguese/English/German \\
Portuguese & Portuguese $(\mathrm{N}=6)$ \\
Portuguese & Portuguese/English \\
Portuguese & Portuguese/English/Spanish $(\mathrm{N}=2)$ \\
Portuguese & Portuguese/Spanish/English/French \\
Portuguese & Portuguese/English/French (reading skills) \\
Portuguese/Moldovan & Portuguese/Moldovan \\
\hline
\end{tabular}

However, to better understand the influence of the English language in the identity construction of young adults in Portugal, it seems appropriate to refer to three studies which deal with central features of the use of English among learners in Portugal.

\section{Complementary study 1: Students' attitudes toward language ownership}

In this study, students $(\mathrm{N}=247)$ at four higher education institutions in Portugal (University of Evora, University of Lisbon, School of Tourism and Hotel Management of Estoril, School of Education of the Polytechnic Institute 
International Journal of Applied Linguistics \& English Literature

ISSN 2200-3592 (Print), ISSN 2200-3452 (Online)

Vol. 1 No. 7; November 2012 [Special Issue on Applied Linguistics]

of Beja) responded to a quantitative and qualitative survey (questionnaire and interview) (Guerra, 2009) which, among other issues, identified their attitudes toward ownership of the English language.

\subsection{Ownership of language}

Widdowson (1994) provides a clear analysis of how the concept of language ownership can be approached. Widdowson suggests that the general assumption in ELT is that the English language belongs to the English, the speakers of proper and genuine English and those who control the language. Such an idea, he claims, is linked to an attitude of preservation of the language. Moreover, this preservation presupposes the authority of native speakers of Standard English. However, Widdowson stresses that Standard English serves the purpose of "a particular community, expressive of its identity, its conventions, and values" (p.381). In other words, it serves the communal or cultural purposes rather than the communicative functions of its community. But Widdowson recognizes that Standard English is an international language, no longer property of England or any other country where it is used as a native language: "It serves a whole range of different communities and their institutional purposes and these transcend traditional communal and cultural boundaries" (p.382). In a sense, these communities, as language creators, are owners of the language.

In the questionnaire, the concept of ownership is suggested through two pairs of statements:

English is:

(a.1) a language which belongs to its native speakers;

(a.2) a language which belongs to whoever uses it;

(b.1) the language spoken in the UK, US, Australia, Canada, New Zealand,...;

(b.2) a global language for international communication.

In each pair, one of the statements refers to the national affiliation of the language (a.1 and b.1) while the other two statements associate English with its international use (a.2 and b.2).

When asked to choose the statement which characterized their opinion about ownership of the English language (a.1 or a.2), English as "a language which belongs to whoever uses it" was chosen by $85 \%$ of the students. Regarding their opinion about the international or national scope of English (b.1 or b.2), the statement that identified English as "a global language for international communication" was picked by $96.7 \%$ of the students.

In the interviews, some subjects perceived English as a language of international communication even though the link with native speakers was not ignored (p.229):

"Nowadays, besides belonging to its native speakers, English is the language of communication and connection among every country, it is the English language which allows for this. It doesn't belong exclusively to its native speakers. Probably it belongs more to the natives but it belongs to everybody."

Similarly, ownership was related to language competence by others:

"I think it's a universal thing. The owners of the English language are the natives but the non-natives can be on the same level. In general, there's no owner to the language."

However, one subject seemed to incorporate the idea of international English and its consequences to language ownership:

"I believe nowadays English is less and less British. There are fewer speakers of standard English, British English, where English belongs only to the English people. Because nowadays English belongs to everybody. And each one has his own English, even through the internet people make up new words, new abbreviations so the English language is becoming less English."

\section{Complementary study 2: Students' attitudes toward the emergence of a Portuguese variety of English (Portuguese English)}

Pernão (2010) carried out a quantitative and qualitative survey (questionnaire and interview) with students $(\mathrm{N}=$ 109) at eleven $1^{\text {st }}$ cycle/B.A. courses at the University of Evora, Portugal who were taking English language subjects aiming at understanding some of the consequences of the globalization of English in the students' use and perception of the language. More specifically, it attempted to examine the existence or not of the influence of specific Portuguese features in the English used by these students and the consequences it may or may not have for the future use of English in Portugal.

5.1 Portuguese English

Page | 121 


\section{International Journal of Applied Linguistics \& English Literature}

ISSN 2200-3592 (Print), ISSN 2200-3452 (Online)

Vol. 1 No. 7; November 2012 [Special Issue on Applied Linguistics]

In the questionnaire, five questions were asked to identify the students' attitudes toward the English they use and the possibility of the emergence of Portuguese English: (1) accepting the features of own English vs. pursuing a native target, (2) attitudes toward own accent vs. pursuing a native target, (3) attitudes toward mistakes, (4) considering the possibility of a Portuguese variety of English, and (5) identifying oneself with Portuguese English.

5.1.1 Accepting the features of own English vs. pursuing a native target

Students were asked to choose the statement with which they identified the most as far as their spoken and written English is concerned:

From the statements given below, choose the one with which you identify the most:

a) I identify myself with the English spoken and written by me even though I know it is not identical to a native model;

b) I accept it but I would like to get closer to a native model;

c) I do not identify myself with the English that I speak and write.

Slightly over half of the students chose option b) whereas 39\% opted for a). Table 6 shows the results.

Table 6. Students' attitudes to overall use of English and native models

\begin{tabular}{lc}
\hline Statements & $\mathrm{N}(\%)$ \\
\hline a) & $43(39 \%)$ \\
b) & $55(51 \%)$ \\
c) & $11(10 \%)$ \\
N/A & 0 \\
Total & $109(100 \%)$ \\
\hline
\end{tabular}

Pernão concluded that "half of the students wish their English would be different and closer to the patterns that constitute a native model, (...) an indication that students believe proximity to a native model is considered to be more correct and to be a 'better type' of English" (p.54). Apparently, "there is a sense of acceptance towards the English developed and utilized by them" although "there are slightly more subjects who would like to modify it so as to make it closer to a native model" (p.54).

5.1.2 Attitudes toward own accent vs. pursuing a native target

Students were also asked in the questionnaire about their attitudes toward their pronunciation and how the Portuguese language may have influenced it:

Concerning your speaking skills, when you speak English, you consider that:

a) I do not have an accent;

b) I do have an accent but I accept it;

c) I have an accent but I would like to be closer to a spoken model of the native of English.

The answers provided show that students were slightly divided when speculating about their pronunciation. Table 7 shows the results.

Table 7. Students' attitudes to their accent and native models

\begin{tabular}{lc}
\hline Statements & $\mathrm{N}(\%)$ \\
\hline a) & $32(29 \%)$ \\
b) & $25(23 \%)$ \\
c) & $52(48 \%)$ \\
N/A & 0 \\
Total & $109(100 \%)$ \\
\hline
\end{tabular}




\section{International Journal of Applied Linguistics \& English Literature}

ISSN 2200-3592 (Print), ISSN 2200-3452 (Online)

Vol. 1 No. 7; November 2012 [Special Issue on Applied Linguistics]

Pernão states that although "approximately half of the inquired group recognizes having an accent but would like to (...) be closer to a native model" (p.56), pronunciation seems to be a more divisive subject for students than their overall use of English. She explains that this might be due to "the pressure students feel (...) to speak like natives or because speaking with an accent is socially understood as 'speaking bad English"” (p.56).

\subsubsection{Attitudes toward mistakes}

The following question dealt with the students' attitude toward the mistakes made by Portuguese speakers of English:

What do you think about the mistakes on spoken and written language made by the Portuguese speakers of English?

a) I do not consider them mistakes but features of the English language spoken in Portugal;

b) I consider them mistakes but I accept them;

c) I consider them mistakes that should be corrected so that we can achieve spoken and written English identical or as close as possible to that of the native speakers of English.

Results can be seen in Table 8 .

Table 8. Students' attitudes to mistakes

\begin{tabular}{lc}
\hline Statements & N (\%) \\
\hline a) & $9(8 \%)$ \\
b) & $26(24 \%)$ \\
c) & $74(68 \%)$ \\
N/A & 0 \\
Total & $109(100 \%)$
\end{tabular}

The great majority of students believe mistakes should be corrected to be closer to native English. Pernão explains that this tendency is due to the use of the word 'mistakes', which may have influenced the students' reaction to the question. She adds that the "word was intentionally placed so that it could measure the degree of openness of the students" (p.59) to their occurrence as features of the English spoken in Portugal, or Portuguese English, rather than being seen as mistakes.

5.1.4 Considering the possibility of a Portuguese variety of English

Students were also asked to agree or disagree with the possibility of a variety of Portuguese English:

Do you consider the existence in the future of an English variety with features coming from the Portuguese language (Portuguese English) possible? Why?

a) Yes

b) No

Results show that most students do not agree with the existence of Portuguese English (see Table 9 for results).

Table 9. Students' opinion regarding Portuguese English

\begin{tabular}{lc}
\hline Statements & N $(\%)$ \\
\hline Yes & $17(16 \%)$ \\
No & $91(83 \%)$ \\
N/A & $1(1 \%)$ \\
Total & $109(100 \%)$ \\
\hline
\end{tabular}

Pernão is not surprised at the students' negative reaction to an English variety with characteristics of the Portuguese language "since students had already stated in the previous answers a tendency towards a native model of English” (p.60). 


\section{International Journal of Applied Linguistics \& English Literature \\ ISSN 2200-3592 (Print), ISSN 2200-3452 (Online)}

Vol. 1 No. 7; November 2012 [Special Issue on Applied Linguistics]

In the interviews, some students explained why they denied the possibility of the appearance of Portuguese English. In short, four factors could be identified: (1) cultural and linguistic specificity; (2) the maintenance of the original form of each language; (3) the universality of English; and (4) the capacity of the Portuguese to speak English well. The following are some examples of students' remarks (61):

"I think not, because each language has its history and specificities. English in Portugal may assimilate the lexical issues from the Portuguese Language, but that is it."

"No, I don't think it is possible. Portuguese and English people are very distant people concerning language. The closest to Portuguese English will be the lexical borrowings."

"No, but I consider to be possible the existence of the assimilation of some words coming from the Portuguese language into English."

"No, even though these languages influence each other, altering their own words, there shouldn't be a variety with these characteristics"

5.1.5 Identifying oneself with Portuguese English

Finally, in the following question students were inquired if they would identify themselves with Portuguese English:

Would you identify yourself with "Portuguese English"?

a) Yes

b) $\mathrm{No}$

Predictably, students displayed the same tendency as in the previous questions as the great majority stated they would not feel identified with Portuguese English (see Table 10 for results).

Table 10. Students' identification with Portuguese English

\begin{tabular}{lc}
\hline Statements & N (\%) \\
\hline Yes & $25(23 \%)$ \\
No & $78(71 \%)$ \\
N/A & $6(6 \%)$ \\
Total & $109(100 \%)$ \\
\hline
\end{tabular}

On reflection, most students wanted their English to be closer to a native model and did not believe a variety of Portuguese English to be possible. In other words, subjects did not see themselves as creators of the English language but mere users of a linguistic system which has been transferred onto them. Certainly, such belief reflects upon the construction of their identity as users of the English language. However, it is crucial to identify the learners' attitudes toward the use of English lexicon in their native language discourse.

6. Complementary study 3: Students' attitudes toward the use of English borrowings and how language is used to construct youth identity

Gomes (2008) applied a focus questionnaire to students $(\mathrm{N}=139)$ at the University of Aveiro, Portugal in the $1^{\text {st }}$ cycle/B.A. in Languages and Business Management about their feelings toward the phenomenon of English usage. One section of the questionnaire aimed at finding out about the students' opinions and attitudes toward English usage in Portuguese discourse, such as their use of English borrowings.

\subsection{English borrowings and youth identity}

The questionnaire included one question that addressed the students' attitudes toward the use of English terms in the Portuguese language, and another that inquired their reasons for using English borrowings.

6.1.1 Students' attitudes toward the use of English terms in the Portuguese language

The majority of opinions are either 'positive' or 'indifferent' while few students have either a negative or any other opinion in relation to the use of English in Portuguese. When asked to explain their opinions on the use of English words in Portuguese, some students provided interesting data (pp.98-100):

(it is) "not totally negative but not actually positive because it adulterated our language".

(it is important that it) "did not damage the Portuguese language".

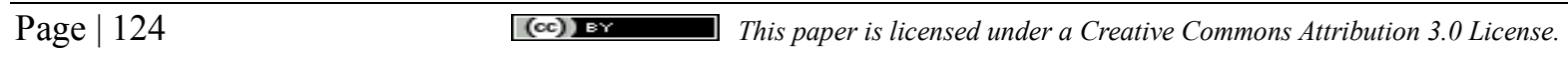


International Journal of Applied Linguistics \& English Literature

ISSN 2200-3592 (Print), ISSN 2200-3452 (Online)

Vol. 1 No. 7; November 2012 [Special Issue on Applied Linguistics]

"it is a bit negative as we can lose part of the Portuguese language".

"it is positive and negative, positive in objective and practical terms, but negative for the richness of the Portuguese language”.

6.1.2 Reasons for using English borrowings

Students were asked to rate in order of importance the reasons why they use English words in their Portuguese discourse. The following are the reasons provided in order of importance (p.116).

1st: English is the lingua franca of the globalised world

2nd: Portuguese society is open to new cultures

3rd: I study English

4th: My friends use them too

5th: It makes me feel an important part of youth culture

6th: People of different ages don't understand them

7th: It irritates people of different ages

Based on the results, Gomes concludes that "the reasons were not related to the fact that the people completing the questionnaires were young people or that English is a language used extensively by young people". Rather than perceiving English as a marker of youth identity, results showed that "what was important in the minds of the students was a feeling of internationality, of belonging to and communicating with the world in general" (p.115).

\section{Overall conclusions}

This paper aimed to explore connections between English learners' own perceptions of their language use and on the discursive construction of identities. After analyzing the data from all studies above (see sections 3, 4, 5 and 6), several conclusions can be drawn:

- Students did not identify their competence in the English language as a marker of their individual identity (see section 3.1);

- As far as the students' identification of their collective identity is concerned, all subjects pointed out the Portuguese language while only half identified the English language as a marker of their collective identity; there was some indication that students considered their competence level in a foreign language so as to consider it a marker of their identity (see section 3.2);

- The overwhelming majority of students recognized English as a language which belongs to whoever uses it and as a global language for international communication (see section 4.1);

- Half of the students would like their English to be closer to a native model (see sections 5.1.1 and 5.1.2);

- Most students believe they make mistakes in English which should be corrected, as opposed to accepting them as features of the English used in Portugal (see section 5.1.3);

- Most students do not believe the existence of a variety of English such as Portuguese English to be possible nor would they identify themselves with such a variety in case it existed (see sections 5.1.4 and 5.1.5);

- Most of the students use English borrowings because English is the lingua franca of the globalized world. Reasons which might be related to the construction of a 'youth identity' only came in 4th ('My friends use them too') and 5th ('It makes me feel an important part of youth culture') places (see section 6.1).

All things considered, it is fair to say that the English language seems not to be a crucial marker in the construction of the identity of Portuguese university students. Some explanations may be proposed. The first is that Portugal is the most linguistically uniform country in Europe. Recently, the Mirandese language, spoken by around 15000 people in northeastern Portugal, became the second official language of the country. In essence, Portugal is a linguistically homogeneous country and, culturally speaking, monolingualism may be part of the identity of the Portuguese. Another reason might be related to the possibility that identifying a foreign language as a marker of one's identity has to do with the user's competence level in the language. Can advanced fluency only lead to the consideration of a foreign language as part of our identity? Finally, the English curricula in Portuguese primary and secondary schools emphasize the role of the native speaker(s) and native culture(s). This might be deterrent to including the English language as a marker of the identity of the Portuguese people. 
International Journal of Applied Linguistics \& English Literature

ISSN 2200-3592 (Print), ISSN 2200-3452 (Online)

Vol. 1 No. 7; November 2012 [Special Issue on Applied Linguistics]

\section{References}

Cerulo, K. A. (1997). Identity construction: new issues, new directions. Annual Review of Sociology, 23, 385-409. http://dx.doi.org/10.1146/annurev.soc.23.1.385

Edwards, J. (2009). Language and identity: An introduction. Cambridge: Cambridge University Press. http://dx.doi.org/10.1017/CBO9780511809842

Gomes, M. (2008). O inglês e a identidade social entre universitários portugueses. (Unpublished Master's thesis). University of Aveiro, Portugal.

Guerra, L. (2009). Teaching and learning English as an international language: Policy, practice and perceptions. Saarbrücken: VDM Verlag.

Norton, B. (1997). Language, identity, and the ownership of English. TESOL Quarterly, 31(3), 409-429. http://dx.doi.org/10.2307/3587831

Pernão, A. (2012). Portuguese English: is it possible? Analysing the emergence of an English variety in Portugal. (Unpublished Master's thesis). University of Evora, Portugal.

Riley, P. (2007). Language, culture and identity: An ethnolinguistic perspective. London: Continuum.

Schöpflin, G. (2001). The construction of identity. Retrieved from

http://www.oefg.at/text/veranstaltungen/wissenschaftstag/wissenschaftstag01/Beitrag_Schopflin.pdf

Widdowson, H.G. (1994). The ownership of English. TESOL Quarterly, 28(2), 377-389.

http://dx.doi.org/10.2307/3587438 